\title{
Whole-exome sequencing in an extended family with myocardial infarction unmasks familial hypercholesterolemia
}

Ingrid Brænne ${ }^{1,2}$, Benedikt Reiz ${ }^{1,2}$, Anja Medack ${ }^{1}$, Mariana Kleinecke ${ }^{1,2}$, Marcus Fischer $^{3}$, Salih Tuna ${ }^{6}$, Christian Hengstenberg ${ }^{4,5}$, Panos Deloukas ${ }^{6,7,8}$, Jeanette Erdmann ${ }^{1,2^{*} \dagger}$, Heribert Schunkert ${ }^{4,5+}$

and Cardiogenics consortium

\begin{abstract}
Background: Familial hypercholesterolemia $(\mathrm{FH})$ is an autosomal-dominant disease leading to markedly elevated low-density lipoprotein (LDL) cholesterol levels and increased risk for premature myocardial infarction (MI). Mutation carriers display variable LDL cholesterol levels, which may obscure the diagnosis. We examined by whole-exome sequencing a family in which multiple myocardial infarctions occurred at a young age with unclear etiology.

Methods: Whole-exome sequencing of three affected family members, validation of the identified variant with Sanger-sequencing, and subsequent co-segregation analysis in the family.

Results: The index patient (LDL cholesterol $188 \mathrm{mg} / \mathrm{dL}$ ) was referred for molecular-genetic investigations. He had coronary artery bypass graft (CABG) at the age of 59 years; 12 out of 15 1st, 2nd and 3rd degree relatives were affected with coronary artery disease (CAD) and/or premature myocardial infarction (MI). We sequenced the whole-exome of the patient and two cousins with premature MI. After filtering, we were left with a potentially disease causing variant in the LDL receptor $(L D L R)$ gene, which we validated by Sanger-sequencing (nucleotide substitution in the acceptor splice-site of exon 10, c.1359-1G > A). Sequencing of all family members available for genetic analysis revealed co-segregation of the variant with CAD (LOD 3.0) and increased LDLC (>190 mg/dL), following correction for statin treatment (LOD 4.3). Interestingly, mutation carriers presented with highly variable corrected (183-354 mg/dL) and on-treatment LDL levels (116-274 mg/dL) such that the diagnosis of FH in this family was made only after the molecular-genetic analysis.

Conclusion: Even in families with unusual clustering of CAD FH remains to be underdiagnosed, which underscores the need for implementation of systematic screening programs. Whole-exome sequencing may facilitate identification of disease-causing variants in families with unclear etiology of $\mathrm{Ml}$ and enable preventive treatment of mutation carriers in a more timely fashion.
\end{abstract}

Keywords: Familial hypercholesterolemia, Myocardial infarction, Whole-exome sequencing

\footnotetext{
* Correspondence: jeanette.erdmann@iieg.uni-luebeck.de

${ }^{\dagger}$ Equal contributors

${ }^{1}$ Institute for Integrative and Experimental Genomics, University of Lübeck, 23562 Lübeck, Germany

${ }^{2}$ DZHK (German Research Centre for Cardiovascular Research), partner site

Hamburg/Lübeck/Kiel, 23562 Lübeck, Germany

Full list of author information is available at the end of the article
} 


\section{Background}

Familial hypercholesterolemia (FH) may explain as much as 20 percent of familial cases with premature coronary artery disease (CAD) [1,2]. Despite well-established criteria for clinical diagnosis and the proven benefits of medical treatment FH remains to be largely under-diagnosed and untreated [3]. In most European populations between $5-15 \%$ of cases are diagnosed [4,5]. It has been considered that many $\mathrm{FH}$ cases are simply overlooked in the large number of CAD patients, a disease usually caused multifactorially by the interplay of common risk factors and common risk alleles $[4,6]$. Moreover, with significant impact, the fact that nowadays most families are small may mask the inherited nature of the disease $[7,8]$.

In cases with suspected $\mathrm{FH}$, family-based cascade screening by either clinical or molecular-genetic instruments is guideline recommended to unravel the autosomal-dominant mode of inheritance and to facilitate medical treatment at a young age (European Society of Cardiology [9], British National Institute for Clinical Excellence (NICE) [10], US Centres for Disease Control and Prevention [11]).

Yet, such testing either using lipid panels paired with clinical diagnostic criteria or molecular-genetic DNA sequencing of the currently known disease-causing genes is vastly under-used $[4,12,13]$. Exceptions are found in the Netherlands and Norway, where national screening programs for mutations in the disease-causing genes LDLR, APOB and PCSK9 have been initiated [4,14,15].

Here, we report on an extended MI-family, which remained without diagnosis until whole-exome sequencing was performed. The index patient was referred to us because of premature MI (CABG at the age of 59) and positive family history for CAD (rather than for elevated LDL-cholesterol levels, LDL-C). His LDL-C was $188 \mathrm{mg} / \mathrm{dL}$, which initially detracted from a clinical suspicion of FH. The family with 15 CAD cases (plus two that are related by marriage) and several untreated mutation carriers illustrates the need for a more systematic employment of molecular $\mathrm{FH}$ testing to increase the awareness and timely initiation of medical treatment.

\section{Methods \\ MI family}

The index patient had suffered from CABG at the age of 59 years. Figure $1 \mathrm{~A}$ depicts the pedigree of the MI family used for whole-exome sequencing. Clinical and angiographic characteristics of the family members available for analysis are described in detail in Table 1. All subjects analyzed in this study gave written informed consent before participating. The local Ethical Committee (University Regensburg, Germany) approved the study.

\section{Exome sequencing}

Whole-exome sequencing was performed as 54 bp pairedend runs on a Genome Analyzer IIx system (Illumina) after in-solution enrichment of exonic sequences (SureSelect Human All Exon $50 \mathrm{Mb}$ kit, Agilent). Reads are mapped to the reference genome, duplicate fragments are marked using Picard and GATK is then used to recalibrate base
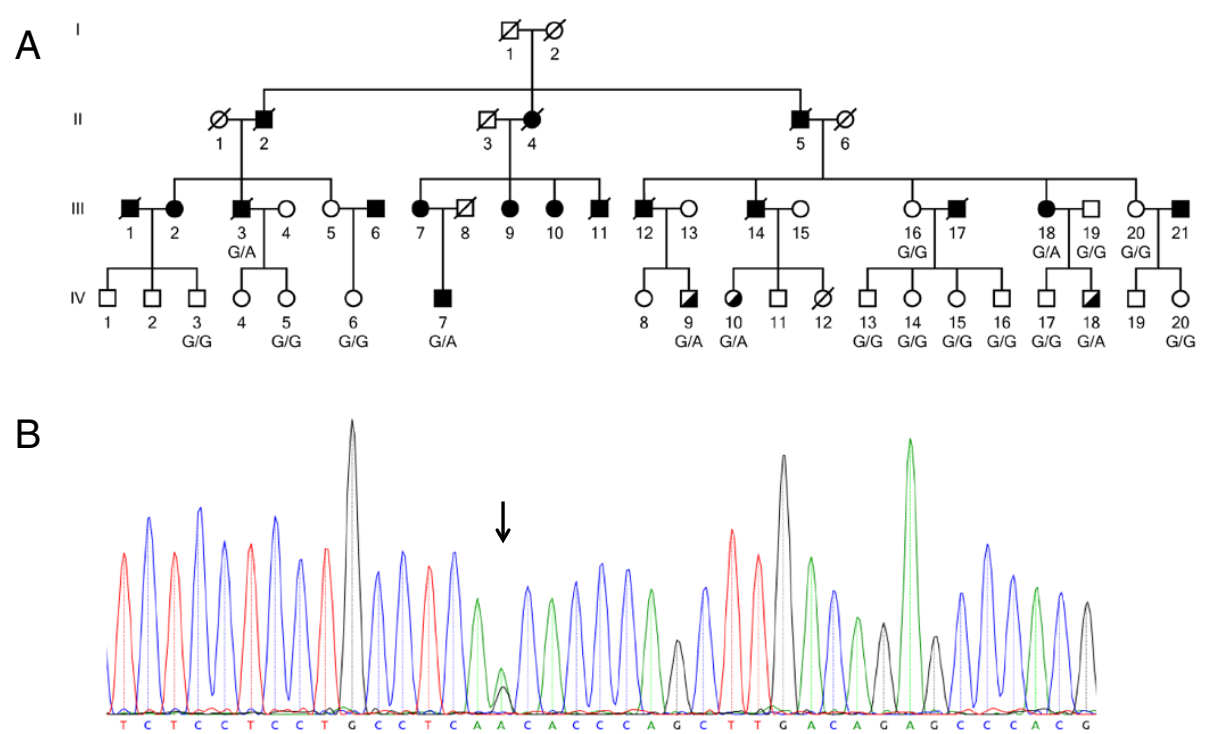

Figure 1 Pedigree of the analyzed family and confirmation of mutation by Sanger sequencing. A) The index patient is IV.7. The family members selected for whole-exome sequencing are III.3, III.18, and IV.7. Elevated LDL-C levels are shown as half filled symbols. Mutation carriers are shown as G/A and non-carriers as G/G. B) Confirmation of the nucleotide substitution in the acceptor splice-site of exon 10, c.1359-1G > A by Sanger sequencing. Shown is the sequence of the index patient IV.7. The black arrow points to the heterozygote position. 
Table 1 Clinical characteristics of family 6652

\begin{tabular}{|c|c|c|c|c|c|c|c|c|c|c|c|c|}
\hline $\begin{array}{l}\text { Family } \\
\text { ID }\end{array}$ & $\begin{array}{l}\text { Pedigre } \\
\text { ID }\end{array}$ & Sex & BMI $\left(\mathrm{kg} / \mathrm{m}^{2}\right)$ & $\begin{array}{l}\text { Age at } \\
\text { first MI } \\
\text { (years) }\end{array}$ & $\begin{array}{c}\text { Age at } \\
\text { first CAD } \\
\text { (years) }\end{array}$ & $\begin{array}{c}\text { LDL-C } \\
\text { (mg/dL) }\end{array}$ & $\begin{array}{l}\text { Statin } \\
\text { therapy }\end{array}$ & $\begin{array}{l}\text { Daily } \\
\text { dose }\end{array}$ & $\begin{array}{l}\text { Hyper- } \\
\text { cholesterol- } \\
\text { emia }^{1 \#}\end{array}$ & Hyper-tension $^{2 \#}$ & Diabetes $^{3 \#}$ & Smoking $^{4 \#}$ \\
\hline 6652501 & III.2 & 2 & 28.5 & & 58 & 252 & Atorvastatin & 20 & 1 & 1 & 2 & 1 \\
\hline 6652502 & III.3 & 1 & 26.5 & & 55 & 214 & Atorvastatin & 60 & 1 & 1 & 2 & 2 \\
\hline 6652505 & III.16 & 2 & 22.8 & & & 186 & & & 2 & 1 & 2 & 2 \\
\hline 6652506 & |ll.18 & 2 & 25.0 & & 55 & 233 & Atorvastatin & 80 & 1 & 2 & 2 & 1 \\
\hline 6652509 & IV.6 & 2 & 26.4 & & & 184 & & & 2 & 2 & 2 & 1 \\
\hline 6652511 & |II.6 & 1 & 25.9 & 44 & 67 & 189 & Atorvastatin & 10 & 1 & 1 & 2 & 1 \\
\hline 6652512 & III.20 & 1 & 30.5 & & & 136 & Cerivastatin & 0.3 & 1 & 1 & 2 & 2 \\
\hline 6652513 & IV.3 & 1 & 24.2 & & & 96 & & & 2 & 2 & 2 & 2 \\
\hline 6652515 & IV.5 & 2 & 23.4 & & & 171 & & & 2 & 2 & 2 & 1 \\
\hline 6652516 & IV.7 & 1 & 25.2 & & 59 & 188 & Atorvastatin & 40 & 1 & 2 & 2 & 2 \\
\hline 6652518 & III.13 & 2 & 27.3 & & & 156 & & & 2 & 2 & 2 & 1 \\
\hline 6652520 & IV.9 & 1 & 22.5 & & & 142 & Simvastatin & 10 & 1 & & 2 & 2 \\
\hline 6652522 & IV.13 & 1 & 29.4 & & & 166 & & & 2 & 2 & 2 & 1 \\
\hline 6652523 & IV.14 & 2 & 24.2 & & & 168 & & & 2 & 2 & 2 & 2 \\
\hline 6652524 & IV.15 & 2 & 23.5 & & & 130 & & & 2 & & 2 & 2 \\
\hline 6652525 & IV.16 & 1 & 22.7 & & & 145 & & & 2 & 2 & 2 & 2 \\
\hline 6652527 & IV.20 & 2 & 23.4 & & & 143 & & & 2 & & 2 & 1 \\
\hline 6652531 & IV.10 & 2 & 20.9 & & & 116 & Atorvastatin & 60 & 1 & 2 & 2 & 2 \\
\hline 6652533 & IV.12 & 2 & 21.3 & & & & & & & 2 & 2 & 2 \\
\hline 6652534 & III.19 & 1 & 23.1 & & & 115 & & & 2 & 1 & 2 & 2 \\
\hline 6652535 & IV.17 & 1 & 23.2 & & & 184 & & & 2 & 2 & 2 & 2 \\
\hline 6652536 & IV.18 & 1 & 22.8 & & & 274 & Atorvastatin & 20 & 1 & 2 & 2 & 2 \\
\hline
\end{tabular}

$\$: 1$ = male, 2 = female; \#: 1 =yes, $2=$ no; ${ }^{1}$ Blood pressure $>140 / 90 \mathrm{~mm} \mathrm{Hg} ;{ }^{2} \mathrm{LDL}$ cholesterol $>190 \mathrm{mg} / \mathrm{dL}$ or statin therapy; ${ }^{3} \mathrm{History}$ of diabetes mellitus; ${ }^{4}$ History of smoking. Index patient IV.7 in bold.

qualities. We used the human genome assembly hg19 (GRCh37) as reference.

\section{Mutation validation}

We annotated the single nucleotide variants (SNVs) with Annovar [16] using the UCSC database, Exome sequencing project and 1000 Genomes. Protein altering effect was predicted using SnpEFF [17] and avsift (Annovar). Mutation validation was performed by PCR and Sangersequencing of candidate gene region identified by wholeexome sequencing. After confirmation of the variant (Figure 1B), additional affected and unaffected family members were screened considering co-segregation. Primers used for mutation validation and PCR conditions are as following. A set of primers (Left Primer 5 ' -tgtaaaacgacggccagtGAGGCACTCTTGGTTCCATC-3' and Right Primer 5'-caggaaacagctatgaccGTGGATACGCACCCATGAAC-3') was chosen to amplify the region of the LDLR gene encompassing the c.1359-1G > A variant (562 bp length). Standard PCR was carried out in a $10 \mu \mathrm{l}$ volume containing $10 \mathrm{ng}$ genomic DNA, 5 pmol of each primer and $4 \mu \mathrm{l}$ of Mastermix (VWR International $\mathrm{GmbH}$,
Darmstadt, Germany). Samples were processed in a Sensoquest labcycler with a standard touchdown PCR program (annealing temperature from $61^{\circ} \mathrm{C}-55^{\circ} \mathrm{C}$ ).

\section{Results and discussion}

We analyzed an extended German MI-family consisting of 53 members of whom 13 were affected with CAD and/ or MI (Figure 1A). Of these, 18 family members were available for genetic analysis. Based on the phenotypic presentation in this family, we suspected an autosomal dominant mode of inheritance. Therefore, we decided to carry out whole-exome sequencing of three affected family members to unravel the genetic cause of CAD/MI in this family.

The amount of disease-unspecific variants present in the downstream analysis of whole-exome sequencing is largely influenced by the subset of family members that are selected for the initial analysis $[18,19]$. To optimize the variant search, one strategy is to select distantly related family members. Whereas siblings share $50 \%$ of the genetic variants, cousins share only $12.5 \%$ [20]. Hence, we selected cousins instead of siblings to reduce the 
number of disease-unspecific variants and to increase the chance for identifying the truly disease-causing variants (Figure 1A; III.3, III.18, and IV.7) [21,22].

To identify the causal variant in this family, we based our filtering on three assumptions: (1) the variant is inherited in an autosomal dominant mode of inheritance; (2) the variant is very rare $(<0.1 \%)$ in the general population; and (3) most affected family members carry the variant (high penetrance).

The sequencing was performed on a Genome Analyzer llx system (Illumina) after in-solution enrichment of exonic sequences. The exome sequencing revealed an average read depth of 155 with minimum $84 \%$ of the target regions covered at least 20X.

Whole-exome sequencing revealed around 39,000 variants in total and approximately 20,000 located in exonic regions. We filtered the variants using the frequencies stated in 1000 Genomes (1 kG, Annovar version 1000g2012apr), Exome Sequencing Project (ESP, Annovar version 6500) and in internal exome data (8 samples sequenced with the same platform). Around 1,800 variants were found with a frequency less than $0.1 \%$ in ESP and $1 \mathrm{kG}$. In a next filtering step, we kept only variants that were conserved and outside regions of segmental duplication, leaving $\sim 825$ variants. To identify variants with potentially severe function-altering effects, we filtered all variants based on avsift score $>0.05$ and "HIGH" effect predicted using Annovar and SnpEFF. These variants are either amino acid changes, stop gain, stop loss or splice-site mutations (more details can be found in Table 2). Only one variant, a G > A substitution in the acceptor splice-site of exon 10 in the $L D L R$ gene (IVS9-1G > A or c.1359-1G > A), was shared by the three sequenced family members and was validated by Sanger-sequencing.

This G > A substitution results in the loss of a splice-site with a predicted splice-site score of -4.2 for the variant versus 6.8 for the reference allele [http://rulai.cshl.edu]. We genotyped this variant in all family members available

Table 2 Bioinformatic filtering of the family members that were exome sequenced

\begin{tabular}{lrrrr}
\hline Filter & III.3 & III.18 & IV.7 & Mean \\
\hline Total aligned variants & 38,702 & 38,408 & 38,775 & 38,628 \\
Variants (exome) & 20,344 & 20,387 & 20,173 & 20,301 \\
Not in internal controls & 1,995 & 2,123 & 2,097 & 2,072 \\
Variants with frequency & 1,643 & 1,885 & 1,864 & 1,797 \\
$<0.1 \%$ in 1000G and ESP & & & & \\
Conserved and no & 713 & 900 & 862 & 825 \\
segmental duplication & & & & 15 \\
snpEFF = HIGH and AVSIFT $<0.05$ & 7 & 18 & 19 & 1 \\
Shared variants & & & & \\
\hline
\end{tabular}

The data was annotated using annovar [16] (Version August 2013). Functional prediction was performed with snpEFF [17] (build 2014-01-16) and AVSIFT (Annovar). for genetic analysis to check for co-segregation with the disease. There were 18 (one related by marriage) family members available for genotyping. Of these, three were affected and these carried the LDLR-variant. Of the 14 unaffected family members, which were not related by marriage, three carried the variant. The three unaffected mutation carriers were, at the time included in this analysis, 48, 54 and 54 years old. Since MI is a late-onset disease, we expect the disease to occur late in life. Hence, the affection status regarding MI must be considered unknown at this point.

Since the 1990s, it is well established that mutations in the $L D L R$ gene are the major cause for familial hypercholesterolemia [1,23]. Around $90 \%$ of all known diseasecausing mutations (more than 1,800 mutations are listed in HGMD (version 2013.4)) for FH are found in the $L D L R$ gene $[3,24,25]$. FH is also caused by mutations in the $A P O B$ and PCSK9 genes, with frequencies of around 5\% and $\sim 1 \%$ respectively $[4,26]$.

We compared the LDL-C levels of the family members that carry the variant with those that do not carry the variant. The results showed that the variant co-segregates with increased LDL-C levels (LOD 4.3). The average LDL$\mathrm{C}$ levels were significantly increased in mutation carriers compared with non-mutation carriers $(279 \mathrm{mg} / \mathrm{dL}$ versus $155 \mathrm{mg} / \mathrm{dL}$ ). However, the plasma levels were highly variable ranging from $183 \mathrm{mg} / \mathrm{dL}$ to $354 \mathrm{mg} / \mathrm{dL}$; this fact misled the clinical diagnosis in the index patient (188, corrected for statin use $279 \mathrm{mg} / \mathrm{dL}$ ). To estimate the functional implication of the identified variant, we systematically searched the literature. This revealed that the LDLR variant has been previously described as disease-causing in families with FH $[27,28]$.

This variant is reported to originate from the south of the Netherlands and to significantly increase the LDL-C levels and hence cause a higher risk of premature CVD. The risk increase was found to be $15.95 \%$ for mutation carriers compared to unaffected relatives [29]. In our analyzed family, all but one mutation carrier have LDL-C levels above $190 \mathrm{mg} / \mathrm{dL}$. This result clearly underlines the previous reported significant risk increase.

The variant cause an abnormally spliced transcript, which results in a deletion of $7 \mathrm{bp}$ and a frame shift with premature termination [30]. The deletion affects the normal acceptor splice site in the 9th intron. This leads to a cryptic splice site that consist of the 6th and 7th nucleotide of exon 10.

The variant is likely to cause haploinsufficiency because of the truncated transcript and hence nonsense-mediated decay. However, even a protein product would lead to a loss-of-function of the receptor since several important domains of the receptor would be missing, such as the crucial transmembrane region, the C-terminal part of the epidermal growth factor precursor homology domain, the 
O-linked sugar domain, the membrane-spanning domain, and the cytoplasmic domain. Other variants lacking these domains have been reported to have reduced activity (around 2\%) and are classified as null allele (class 1) mutations [31]. These mutations produce normal mRNA transcripts, however, in reduced concentration [32], which explains the increased risk of $\mathrm{FH}$ caused by this mutation.

With $\mathrm{FH}$ as the underlying cause of $\mathrm{MI}$ in this family, we could have anticipated a mutation in the LDLR gene. However, the index patient was referred to us and included in our study with the diagnosis of premature MI/ CABG and positive family history for CAD.

The varying LDL-C levels in this family had initially hindered the diagnosis of FH. It is, however, well known, that the LDL-C levels may vary remarkably even among individuals with the same mutation. One explanation for this is that other modifying factors are present [31]. One such mutation was described by Hobbs et al. [31]. They reported a family in which one-third of the mutation carriers have LDL concentrations below the 90th percentile. They suggested the existence of a dominant gene that suppresses the effect of the LDL receptor mutation. Hence, the fact that one of our mutation carriers have LDL-C levels below $190 \mathrm{mg} / \mathrm{dL}$ might have similar explanation and demonstrate the complexity of even expected monogenic disease variants.

The result of this study underlines the power of wholeexome sequencing approaches to identify disease-causing variants. Whole-exome sequencing is a promising tool to identify the cause of a disease in families with unclear etiology of MI.

\section{Conclusion}

We strongly suggest that whole-exome sequencing can be used for stratified medicine. If we know the diseasecausing variant in affected families, we can enable specific preventive treatment of so-far unaffected mutation carriers and this may prevent or delay the onset of the disease. In addition, having overseen FH in the family at hand, we believe that the systematic sequencing of $L D L R$ pathway genes may accelerate the diagnostic work-up.

\section{Competing interests}

The authors declare no competing interests.

\section{Authors' contributions}

JE, HS, and PD designed the study; IB, BR, AM, ST, and MK performed the analysis; MF and $\mathrm{CH}$ collected the family data; $\mathrm{IB}$, JE, and HS wrote the manuscript. All authors read and approved the final manuscript.

\section{Acknowledgements}

We thank all the family members who participated in this research. Without the continuous support of these patients over more than fifteen years, the present work would not have been possible. We like to thank Sandra Wrobel for technical assistance. We also would like to thank Drs. Björn Mayer, Ute Hubauer, and Anika Großhennig for help with the German Myocardial Infarction Study.
The study was supported by the FP6/FP7 EU funded integrated projects Cardiogenics (LSHM-CT-2006-037593) and CVgenes@target (HEALTH-F2-2013601456), and the local focus program "Medizinische Genetik" of the Universität zu Lübeck. IB is funded by the DFG-funded Excellence Cluster Inflammation at interfaces. Principle investigators of the Cardiogenics Consortium not included in the authors list are Willem H. Ouwehand ${ }^{1}$, Alison Goodall ${ }^{2}$, Nilesh J Samani ${ }^{2}$, and Francois Cambien ${ }^{3} .1$ Department of Haematology, University of Cambridge, Long Road, Cambridge, CB2 2PT, UK and National Health Service Blood and Transplant, Cambridge Centre, Long Road, Cambridge, CB2 2PT, UK; 2 Department of Cardiovascular Sciences, University of Leicester, Glenfield Hospital, Groby Road, Leicester, LE3 9QP, UK; 3 INSERM UMRS 937, Pierre and Marie Curie University (UPMC, Paris 6) and Medical School, 91 Bd de l'Hôpital 75013, Paris, France.

\section{Author details}

${ }^{1}$ Institute for Integrative and Experimental Genomics, University of Lübeck, 23562 Lübeck, Germany. 'ZZHK (German Research Centre for Cardiovascular Research), partner site Hamburg/Lübeck/Kiel, 23562 Lübeck, Germany. ${ }^{3}$ Klinik und Poliklinik für Innere Medizin II, Universitätsklinikum Regensburg, 93053 Regensburg, Germany. ${ }^{4}$ Deutsches Herzzentrum München and Medizinische Klinik, Klinikum rechts der Isar, Technische Universität München, 80636 München, Germany. ${ }^{5}$ DZHK (German Centre for Cardiovascular Research), partner site Munich Heart Alliance, 80636 Munich, Germany. ${ }^{6}$ Wellcome Trust Sanger Institute, Wellcome Trust Genome Campus, Hinxton CB10 1SA, UK. ${ }^{7}$ William Harvey Research Institute, Barts and The London School of Medicine and Dentistry, Queen Mary University of London, London, UK. ${ }^{8}$ Princess Al-Jawhara Al-Brahim Centre of Excellence in Research of Hereditary Disorders (PACER-HD), King Abdulaziz University, Jeddah 21589, Saudi Arabia.

Received: 4 March 2014 Accepted: 21 August 2014

Published: 26 August 2014

\section{References}

1. Goldstein JL, Schrott HG, Hazzard WR, Bierman EL, Motulsky AG: Hyperlipidemia in coronary heart disease. II. Genetic analysis of lipid levels in 176 families and delineation of a new inherited disorder, combined hyperlipidemia. J Clin Invest 1973, 52:1544-1568.

2. Neefjes LA, Ten Kate GJ, Alexia R, Nieman K, Galema-Boers AJ, Langendonk JG, Weustink AC, Mollet NR, Sijbrands EJ, Krestin GP, de Feyter PJ: Accelerated subclinical coronary atherosclerosis in patients with familial hypercholesterolemia. Atherosclerosis 2011, 219:721-727.

3. Talmud PJ, Shah S, Whittall R, Futema M, Howard P, Cooper JA, Harrison SC, Li K, Drenos F, Karpe F, Neil HA, Descamps OS, Langenberg C, Lench N, Kivimaki M, Whittaker J, Hingorani AD, Kumari M, Humphries SE: Use of low-density lipoprotein cholesterol gene score to distinguish patients with polygenic and monogenic familial hypercholesterolaemia: a case-control study. Lancet 2013, 381:1293-1301.

4. Nordestgaard BG, Chapman MJ, Humphries SE, Ginsberg HN, Masana L, Descamps OS, Wiklund O, Hegele RA, Raal FJ, Defesche JC, Wiegman A, Santos RD, Watts GF, Parhofer KG, Hovingh GK, Kovanen PT, Boileau C, Averna M, Boren J, Bruckert E, Catapano AL, Kuivenhoven JA, Pajukanta P, Ray K, Stalenhoef AF, Stroes E, Taskinen MR, Tybjaerg-Hansen A, European Atherosclerosis Society Consensus P: Familial hypercholesterolaemia is underdiagnosed and undertreated in the general population: guidance for clinicians to prevent coronary heart disease: consensus statement of the European Atherosclerosis Society. Eur Heart J 2013, 34:3478.

5. Brice $P$, Burton $H$, Edwards CW, Humphries SE, Aitman TJ: Familial hypercholesterolaemia: a pressing issue for European health care. Atherosclerosis 2013, 231:223-226.

6. CARDIoGRAMplusC4D-Consortium, Deloukas P, Kanoni S, Willenborg C, Farrall M, Assimes TL, Thompson JR, Ingelsson E, Saleheen D, Erdmann J, Goldstein BA, Stirrups K, Konig IR, Cazier JB, Johansson A, Hall AS, Lee JY, Willer CJ, Chambers JC, Esko T, Folkersen L, Goel A, Grundberg E, Havulinna AS, Ho WK, Hopewell JC, Eriksson N, Kleber ME, Kristiansson K, Lundmark P, et al: Large-scale association analysis identifies new risk loci for coronary artery disease. Nat Genet 2013, 45:25-33.

7. Pötzsch $\mathrm{O}$, Weinmann J, Haustein T: Geburtentrends und familiensituation in deutschland. 2012. Available from Statistisches Bundesamt: www.destatis.de.

8. Office-for-National-Statistics: Family size in 2012; 2013. Available from: http://www.ons.gov.uk/. 
9. Reiner Z, Catapano AL, De Backer G, Graham I, Taskinen MR, Wiklund O, Agewall S, Alegria E, Chapman MJ, Durrington P, Erdine S, Halcox J, Hobbs RH, Kjekshus JK, Perrone Filardi P, Riccardi G, Storey RF, David W, Clinical Practice Guidelines Committee of the Spanish Society of C: [ESC/EAS Guidelines for the management of dyslipidaemias]. Rev Esp Cardio/ 2011 64:1168 e1161-1168 e1160.

10. Minhas R, Humphries SE, Qureshi N, Neil HA, Group NGD: Controversies in familial hypercholesterolaemia: recommendations of the NICE Guideline Development Group for the identification and management of familial hypercholesterolaemia. Heart 2009, 95:584-587. discussion 587-591.

11. Third Report of the Expert Panel on Detection, Evaluation, and Treatment of High Blood Cholesterol in Adults (Adult Treatment Panel III). [http://www.cdc.gov/]

12. Benn M, Watts GF, Tybjaerg-Hansen A, Nordestgaard BG: Familial hypercholesterolemia in the danish general population: prevalence, coronary artery disease, and cholesterol-lowering medication. J Clin Endocrinol Metab 2012, 97:3956-3964.

13. Goldberg AC, Hopkins PN, Toth PP, Ballantyne CM, Rader DJ, Robinson JG, Daniels SR, Gidding SS, de Ferranti SD, Ito MK, McGowan MP, Moriarty PM, Cromwell WC, Ross JL, Ziajka PE, National Lipid Association Expert Panel on Familial H: Familial hypercholesterolemia: screening, diagnosis and management of pediatric and adult patients: clinical guidance from the National Lipid Association Expert Panel on Familial

Hypercholesterolemia. J Clin Lipidol 2011, 5:S1-8.

14. Umans-Eckenhausen MA, Defesche JC, Sijbrands EJ, Scheerder RL, Kastelein JJ: Review of first 5 years of screening for familial hypercholesterolaemia in the Netherlands. Lancet 2001, 357:165-168.

15. Leren TP, Manshaus T, Skovholt U, Skodje T, Nossen IE, Teie C, Sorensen S, Bakken KS: Application of molecular genetics for diagnosing familial hypercholesterolemia in Norway: results from a family-based screening program. Semin Vasc Med 2004, 4:75-85.

16. Wang K, Li M, Hakonarson H: ANNOVAR: functional annotation of genetic variants from high-throughput sequencing data. Nucleic Acids Res 2010, 38:e164.

17. Cingolani P, Platts A, Wang le L, Coon M, Nguyen T, Wang L, Land SJ, Lu X, Ruden DM: A program for annotating and predicting the effects of single nucleotide polymorphisms, SnpEff: SNPs in the genome of Drosophila melanogaster strain w1118; iso-2; iso-3. Fly (Austin) 2012, 6:80-92.

18. Campbell N, Sinagra G, Jones KL, Slavov D, Gowan K, Merlo M, Carniel E, Fain PR, Aragona P, Di Lenarda A, Mestroni L, Taylor MR: Whole exome sequencing identifies a troponin T mutation hot spot in familial dilated cardiomyopathy. PLOS One 2013, 8:e78104.

19. Bras J, Guerreiro R, Hardy J: Use of next-generation sequencing and other whole-genome strategies to dissect neurological disease. Nat Rev Neurosci 2012, 13:453-464.

20. Houwen RH, Baharloo S, Blankenship K, Raeymaekers P, Juyn J, Sandkuij LA, Freimer NB: Genome screening by searching for shared segments: mapping a gene for benign recurrent intrahepatic cholestasis. Nat Genet 1994, 8:380-386

21. Erdmann J, Stark K, Esslinger UB, Rumpf PM, Koesling D, de Wit C, Kaiser FJ, Braunholz D, Medack A, Fischer M, Zimmermann ME, Tennstedt S, Graf E, Eck S, Aherrahrou Z, Nahrstaedt J, Willenborg C, Bruse P, Braenne I, Nothen MM, Hofmann P, Braund PS, Mergia E, Reinhard W, Burgdorf C, Schreiber S, Balmforth AJ, Hall AS, Bertram L, Steinhagen-Thiessen E, et al: Dysfunctional nitric oxide signalling increases risk of myocardial infarction. Nature 2013, 504:432-436.

22. Gilissen C, Hoischen A, Brunner HG, Veltman JA: Disease gene identification strategies for exome sequencing. Eur J Hum Genet 2012, 20:490-497.

23. Usifo E, Leigh SE, Whittall RA, Lench N, Taylor A, Yeats C, Orengo CA, Martin AC, Celli J, Humphries SE: Low-density lipoprotein receptor gene familial hypercholesterolemia variant database: update and pathological assessment. Ann Hum Genet 2012, 76:387-401.

24. Futema M, Plagnol V, Whittall RA, Neil HA, Simon Broome Register G, Humphries SE, Uk10K: Use of targeted exome sequencing as a diagnostic tool for Familial Hypercholesterolaemia. J Med Genet 2012, 49:644-649.

25. Soutar AK, Naoumova RP: Mechanisms of disease: genetic causes of familial hypercholesterolemia. Nat Clin Pract Cardiovasc Med 2007, 4:214-225.

26. Austin MA, Hutter CM, Zimmern RL, Humphries SE: Genetic causes of monogenic heterozygous familial hypercholesterolemia: a HuGE prevalence review. Am J Epidemiol 2004, 160:407-420.
27. Peeters AV, Van Gaal LF, du Plessis L, Lombardi MP, Havekes LM, Kotze MJ: Mutational and genetic origin of LDL receptor gene mutations detected in both Belgian and Dutch familial hypercholesterolemics. Hum Genet 1997, 100:266-270.

28. Lombardi P, Sijbrands EJ, van de Giessen K, Smelt AH, Kastelein JJ, Frants RR, Havekes LM: Mutations in the low density lipoprotein receptor gene of familial hypercholesterolemic patients detected by denaturing gradient gel electrophoresis and direct sequencing. J Lipid Res 1995, 36:860-867.

29. Kusters DM, Huijgen R, Defesche JC, Vissers MN, Kindt I, Hutten BA, Kastelein $\mathrm{J}$ : Founder mutations in the Netherlands: geographical distribution of the most prevalent mutations in the low-density lipoprotein receptor and apolipoprotein B genes. Neth Heart J 2011, 19:175-182.

30. Rodningen OK, Tonstad S, Saugstad OD, Ose L, Leren TP: Mutant transcripts of the LDL receptor gene: mRNA structure and quantity. Hum Mutat 1999, 13:186-196.

31. Hobbs HH, Brown MS, Goldstein JL: Molecular genetics of the LDL receptor gene in familial hypercholesterolemia. Hum Mutat 1992, 1:445-466.

32. Hobbs HH, Leitersdorf E, Goldstein JL, Brown MS, Russell DW: Multiple crm- mutations in familial hypercholesterolemia. Evidence for 13 alleles, including four deletions. J Clin Invest 1988, 81:909-917.

doi:10.1186/1471-2261-14-108

Cite this article as: Brænne et al: Whole-exome sequencing in an extended family with myocardial infarction unmasks familial hypercholesterolemia. BMC Cardiovascular Disorders 2014 14:108.

\section{Submit your next manuscript to BioMed Central and take full advantage of:}

- Convenient online submission

- Thorough peer review

- No space constraints or color figure charges

- Immediate publication on acceptance

- Inclusion in PubMed, CAS, Scopus and Google Scholar

- Research which is freely available for redistribution

Submit your manuscript at www.biomedcentral.com/submit
C Biomed Central 